\title{
Microstructural Characterization of Hidalgo/Pachuca Obsidian using Analytical Electron Microscopy
}

Nestor J. Zaluzec ${ }^{1}$, Stavros Nicolopoulos ${ }^{2}$, J.Arenas-Alatorre ${ }^{3}$

1. Argonne National Laboratory, Photon Sciences Division, Argonne, IL, USA.

2. NanoMEGAS SPRL, Brussels, Belgium

3. Instituto de Física, UNAM- México, Cd. Universitaria, CDMX, México 0451

Obsidian is a quenched magmatic liquid which cools to form a solid glassy rock and is found worldwide near many volcanic vents. It has been used for thousands of years to create both tools and jewelry as it can be mechanically worked with suitable skill. Its composition, coloration, and properties varies significantly depending upon the crust zone from which the magmatic fluid erupts. Because of this it is also used in archeological studies to trace exchanges between distant cultural groups. To date, the study of obsidians has for the most part been conducted using macroscopic observation and bulk analytical measurement tools, typically using a combination of large area X-ray fluorescence (XRF) for major elements, while trace elements are measured using alternate techniques such as neutron activation analysis (NAA), and are always combined with visual inspection/classification for color. Generally, Obsidian consists of oxides of $\mathrm{Si}, \mathrm{Al}, \mathrm{Fe}, \mathrm{Ca}, \mathrm{Na}, \mathrm{K}, \mathrm{Ti}, \mathrm{Mn}$ and $\mathrm{Mg}$, with a range of trace elements that can include a large fraction of the periodic table: $\mathrm{Ba}, \mathrm{Ce}, \mathrm{Cl}, \mathrm{Cr}, \mathrm{Co}, \mathrm{Cs}, \mathrm{Cu}, \mathrm{La}, \mathrm{Nb}, \mathrm{Nd}, \mathrm{Ni}, \mathrm{Pb}, \mathrm{Rb}, \mathrm{Sc}, \mathrm{Sr}, \mathrm{Ta}, \mathrm{Th}$, $\mathrm{Y}, \mathrm{U}, \mathrm{Zn}$, and $\mathrm{Zr}$ depending upon the source [1-3]. Overall, $\mathrm{SiO} 2$ generally makes up $>70 \%$ of the content of the glass. The Obsidian studied here is from the Sierra Las Navajas volcanic zone referred today as the Pachuca Source a $250 \mathrm{~km}^{2}$ area near Hidalgo, Mexico.

The Pachuca/Hildago specimen investigated was opaque/grey in coloration, and presents numerous aggregates/inclusions/void visible only under moderate magnification using an optical microscope (Figure 1). Specimens were prepared for AEM work using both ion milling as well as mechanical crushing using a Boron-Carbide mortar \& pestle, the former followed by drop casting from a water suspension on to plasma cleaned holey carbon films. Clear microstructural modifications of the materials was observed in ion milled specimens and therefore only crushed specimen results are reported herein. All AEM measurements were conducted using a Tecnai F20 or Talos F200X, operating at $200 \mathrm{kV}$. X-ray Energy Dispersive Spectroscopy (XEDS) measurements where obtained using either an EDAX Apollo Windowless or an FEI SuperX SDD in a low background Be cup holder. A Gatan GIF 2000 was used for all Electron Energy Loss Spectroscopy (EELS) measurements.

As is expected the main constituent of the Obsidian is glassy Si-Al Oxide which was confirmed by both electron imaging and diffraction (Fig 2), as well as XEDS and EELS. Interestingly there was an obvious absence of any uniform dispersion of nanoparticles in the non-crystalline oxide matrix thus a definitive mechanism for the coloration of the glass could not be established by these measurements. Identification of the aggregates in the Obsidian using AEM is tedious and complex due to the large and diverse size and range of particles which make up the observed aggregates (Fig $3 \& 4$ ). The use of drop cast crushed material also places practical limits on statistical sampling of the microstructure. Nevertheless, micron to nanoscale crystalline particles were found having varying elemental composition (Figure 4) where (trace particles) appear to be different from other provenance samples.. Low Loss EELS confirmed that the Obsidian is different from both pure $\mathrm{Si}$ as well as native crystalline Quartz $\mathrm{SiO} 2$ (Fig 5\&6). Additional measurements are underway to compare other area Obsidian sources and to explore in details the process 
which gives rise to the pronounced color variations.

References:

[1] J.E. Ericson and J. Kimberlin, Archaeometry (1977) 19 \#2 157-166

[2] J.K. Milhasuer etal, Archaeometry, (2017) Published On-line Sept. 2017, doi: 10.1111/arcm.12330

[3] D. Tenorio etal, Journal of Archaeological Science (1998) 25, 229-234

[4] This research used resources in the Center for Nanoscale Materials, an Office of Science user facility, and by Laboratory Directed Research and Development (LDRD) funding from Argonne National Laboratory, provided by the Director, Office of Science supported by the U.S. Department of Energy, Office of Science, Office of Basic Energy Sciences, under Contract No. DE-AC02-06CH11357.

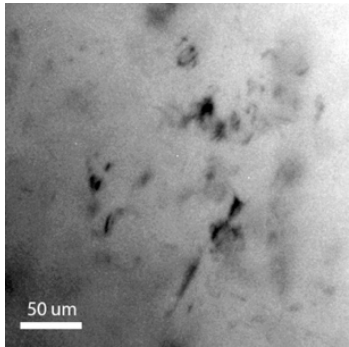

Figure 1. Optical micrograph illustrating small aggregates and voids in the Obsidian matrix

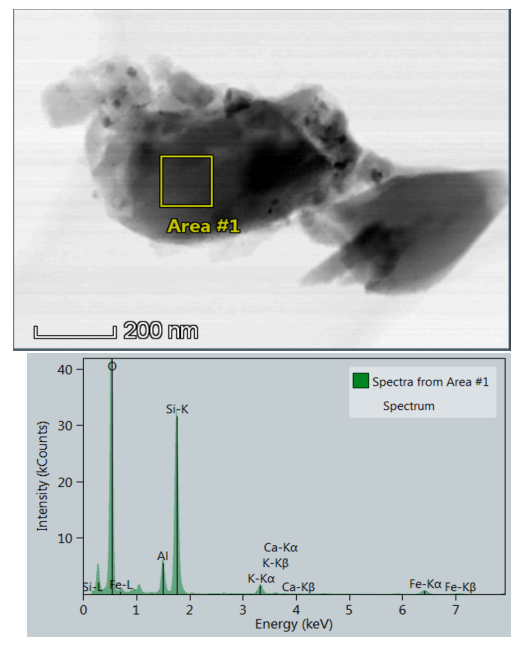

Figure 3. XEDS of Obsidian Matrix of mainly $\mathrm{Si} / \mathrm{Al} / \mathrm{Fe}$ oxides

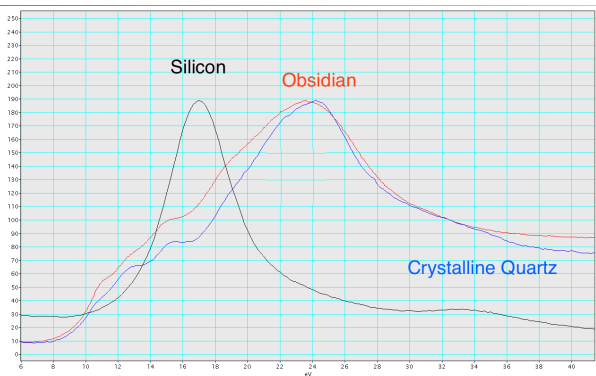

Figure 5. Comparison of Low Loss EELS data from Obsidian, Native Crystalline Quartz, and Silicon. All spectra aligned at Zero Loss
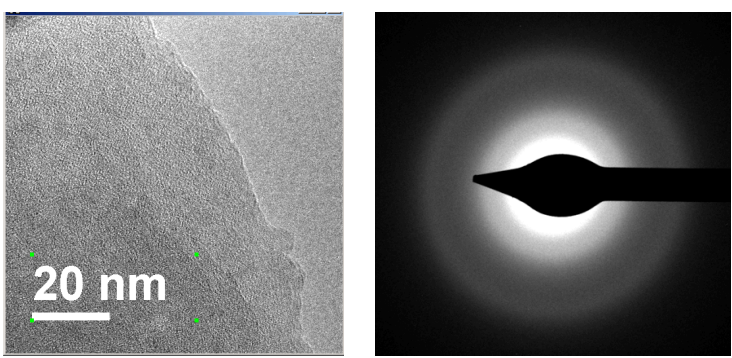

Figure 2. Imaging and Diffraction from Obsidian confirming non-crystalline structure

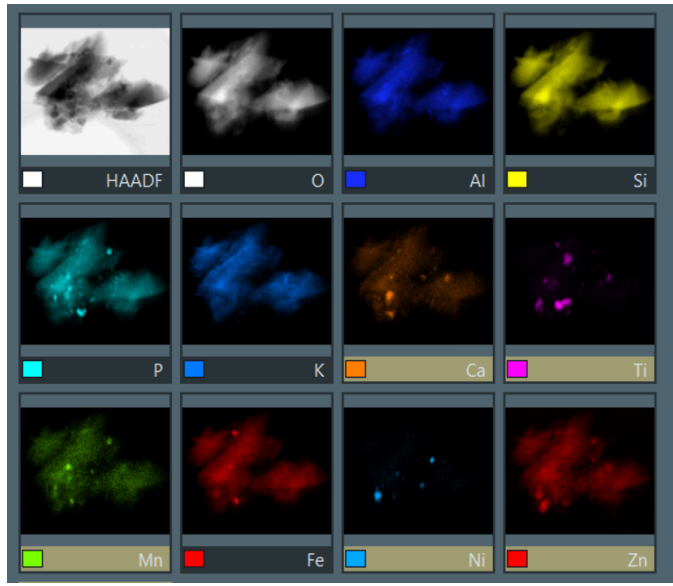

Figure 4. Hyperspectral Images illustrating the diverse elemental distributions in the aggregates.

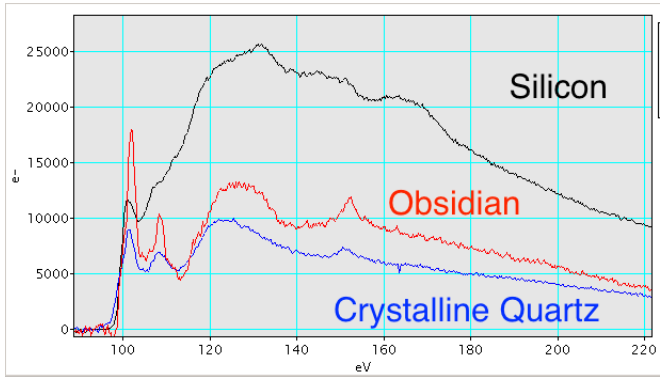

Figure 6. Comparison of Silicon L edge data from Obsidian, Native Crystalline Quartz, and Pure Silicon. All spectra aligned at $\mathrm{Si}_{32}$ Onset 